\title{
NOMADISMO, LITERATURA Y GLOBALIZACIÓN: LAS TRAYECTORIAS PARALELAS DE ROBERTO BOLAÑO Y RODRIGO REY ROSA
}

\author{
Gustavo Guerrero \\ Université de Cergy-Pontoise
}

El chileno Roberto Bolaño (1953-2003) y el guatemalteco Rodrigo Rey Rosa (1958) forman una pareja bastante curiosa y desigual dentro de la generación de escritores latinoamericanos que empieza a darse a conocer en la última década del siglo xx. Aunque sus nombres suelen aparecer juntos cuando se habla de las principales figuras de nuestras hornadas literarias recientes, lo que los separa parece, a primera vista, mucho más importante que lo que los acerca. Sabemos así que el uno es un aprovechado lector de Rimbaud y Cortázar, y un tardío heredero de la tradición de las vanguardias que pone en escena el naufragio de sus ilusiones; mientras que el otro procede originalmente del mundo del cine, es un lector de Borges y Bowles, y está de vuelta de casi todo. Como narradores, el uno apuesta desde temprano por la desmesura de una obra proliferante, modular y abierta, que se plasma en novelas de la extensión de Los detectives salvajes (1998) o 2666 (2004), mientras que el otro trabaja, con una evidente economía de medios, libros de cuentos o breves novelas escritas en una prosa compacta, despojada y diabólicamente precisa. Agreguemos a esta lista de contrastes que, como personajes públicos, el uno adopta hasta el final la pose del poeta maldito que cultiva el escándalo y cuyas declaraciones suelen ser altisonantes, provocadoras e hirientes; mientras que el otro se guarda de intervenir en los medios y, durante muchos años, cultiva más bien el silencio y la invisibilidad, para escapar de la difusión de sus opiniones y su persona.

Hay que rendirse a la evidencia: a primera vista, los dos parecen, en efecto, demasiado diferentes como para que un paralelismo entre ambos pueda re- 
vestir algún interés. $Y$, sin embargo, es sabido que no solo se conocieron sino que mantuvieron durante varios años una peculiar relación en la que se confundieron la amistad, la admiración mutua y también -y esto es lo que importa aquí- el intento por esbozar una imagen distinta del escritor latinoamericano en los nuevos escenarios internacionales surgidos con la globalización. No sé cuánta voluntad o empeño hayan puesto realmente en ello, ni cuánto resulte del cambio de época, de escala y de paradigma cultural en que los dos participan en los años noventa. Pero lo cierto es que nada los aproxima tanto como la manera en que el uno y el otro construyen una cierta figura del escritor que los representa y que representa a buena parte de su generación. El propio Bolaño nos invita a descubrir especularmente esa figura en dos cortas semblanzas que nos dejó de su amigo, como para confirmar aquella idea de Ricardo Piglia (2001: 13) según la cual la crítica es siempre una forma moderna y reflexiva de la autobiografía.

La primera va infusa en la nota "El estilete de Rodrigo Rey Rosa", que es, en realidad, una reseña o una suerte de comentario del libro de cuentos del guatemalteco Ningún lugar sagrado (1998). Allí no solo celebra la elegancia, la precisión y la sabiduría de una prosa capaz de proyectar siempre una sombra inquietante detrás las palabras y los hechos que describe -"leerlo es aprender a escribir", sostiene Bolaño (2004: 141)-. Además, traza de seguido un retrato del autor que no tiene nada de trivial ni de desinteresado:

Hasta hace poco vivía en Guatemala y no tenía casa propia: un día se alojaba con su madre, otro día con su hermana, el resto del tiempo en casa de amigos. Una noche hablamos por teléfono durante casi dos horas: acababa de llegar de Mali. Ahora está en la India, escribiendo un libro que no sabe si terminará o no. Me gusta imaginarlo así: sin domicilio fijo, sin miedo, huésped de hoteles de paso, en estaciones de autobuses del trópico o en aeropuertos caóticos, con su ordenador portátil o con una libreta de tapas azules... (Bolaño 2004: 141)

La segunda semblanza, "Rodrigo Rey Rosa en Mali, creo", la escribe unos dos o tres años más tarde, cuando Rey Rosa publica en España su novela Piedras encantadas (2002). Se trata, en más de un sentido, de una continuación o una amplificación del texto anterior, como ocurre a menudo con la producción intertextual de Bolaño. Así, después de saludar al guatemalteco como al escritor más riguroso y trasparente de su generación, el que mejor teje sus historias y más las ilumina, vuelve a aquella conversación telefónica sobre el viaje a Mali y nos narra en tres cortos párrafos lo que entonces su amigo le contó. Resumo: el vuelo hasta una capital africana y luego los varios días en autobús hasta un pueblo del interior donde de pronto se acaba la carretera y se abre una pista hacia el desierto. A continuación, el camino hasta un río y la lenta navegación aguas arriba hasta una minúscula aldea donde le espera una casa de ladrillos de una sola habitación y donde uno de los escasos muebles es un arcón que contiene varios libros.

Durante algunos días permanece en la aldea, que apenas si tiene las suficientes cabañas como para merecer ese nombre. Compra comida a los lugareños, bebe té a orillas del río, da largos paseos hasta el borde del desierto. Un día termina 
de leer el libro que ha cogido del ya legendario arcón y entonces lo devuelve a su lugar, cierra la casa y se marcha. Cualquier otro hubiera emprendido de inmediato el camino de regreso. Rey Rosa, sin embargo, sale de la aldea, como se suele decir, por la parte de atrás, no por la parte del río, y se dirige a unas montañas. He olvidado el nombre de estas. Sólo sé que al atardecer adquieren un tono azulado que pasa, paulatinamente, del azul pastel al azul metálico. La oscuridad, por descontado, lo sorprende caminando por el desierto y aquella noche duerme entre alimañas.

Al día siguiente reemprende el camino. Y así hasta llegar a las montañas, que encierran pequeños valles estériles, en donde el mar de arena va desgastando las rocas. Aún pasa allí una noche más. Luego regresa a la aldea, al río, al pueblo, al autobús, a la capital y al avión que lo lleva hasta París, en donde por entonces vivía. (Bolaño 2004: 200)

La historia concluye en el presente de la llamada, con un cambio de frases entre los dos amigos que pone fin a la conversación: Bolaño le confiesa a Rey Rosa que un viaje así lo habría matado y este le contesta, impasible, que, en realidad, no era para tanto. Pero lo esencial, como siempre, está en otra parte: en otro texto de Bolaño contemporáneo del anterior y donde se narra un episodio en la vida de su personaje y álter ego Arturo Belano. Me refiero al cuento intitulado "Fotos", que corre en el volumen Putas asesinas (2002). En él nos encontramos con una escena que parece sacada de la llamada telefónica de Rey Rosa o que, en cualquier caso, presenta evidentes afinidades con esa anécdota no solo por su ubicación en una aislada y diminuta aldea africana junto al desierto, sino por la soledad que rodea a un personaje cuya única compañía, en tan lejano pago, es curiosamente un libro de poesía francófona que no se sabe de dónde salió ni cómo llegó hasta allí (Bolaño 2002: 197-205). Para algunos críticos, "Fotos" sería como un capítulo suplementario de Los detectives salvajes (1998) donde se narraría la muerte de Belano en Liberia, omitida en la novela (Manzi 2002: 159). Lo cierto es que, bien vistos, los vínculos con la semblanza de Rey Rosa no parecen menos significativos aunque es difícil saber cómo relacionar ambos textos, si es la biografía de Rey Rosa la que se recicla en el cuento de Belano o el cuento de Belano el que se nutre del relato de Rey Rosa.

Sea cual fuere el orden (habría que revisar los manuscritos para saberlo y acaso tampoco en ellos encontremos la respuesta), lo innegable es que la intertextualidad instaura aquí un juego de espejos entre el amigo de carne y hueso y el personaje de papel y pluma, o, mejor, entre los dos amigos de carne y hueso y el personaje de papel y pluma, pues, como es bien sabido -hay que insistir en ello-, Arturo Belano es el álter ego del propio Roberto Bolaño. Por su intermedio, los dos escritores acaban así confundiéndose, más allá de los textos, en una sola imagen. Digamos, para abreviar, que el chileno nos representa a Rey Rosa como a un Arturo Belano y se representa a sí mismo como Arturo Belano, formulando de esta suerte una ecuación de la que resulta la figura del escritor que los reúne a los tres y que, a todas luces, no es otra que la figura del nómada.

Es mucho lo que se ha escrito ya sobre la vida vagabunda y azarosa de Bolaño, hasta el punto que ha llegado a atribuirse parte de su éxito en los Estados 
Unidos a esa fama de rolling stone que lo acompañaba y que habría permitido asociarlo, en el horizonte norteamericano, con Kerouac y con la Beat Generation (Castellanos Moya 2009). También, aunque en menor grado, la crítica ha insistido en el perfil viajero de Rey Rosa y, como nos lo muestra el propio Bolaño, ha destacado su espíritu aventurero (Gray 2007). No ha faltado, pues, quien haya escrito sobre el nomadismo del uno y el otro ni quien haya analizado el influjo de dicha movilidad en sus escritos, en sus públicos y en el modo de difusión de sus obras. Sin embargo, lo que me interesa, en estas páginas, es tratar de contextualizarlo específicamente dentro de las estrategias de una generación latinoamericana emergente que hallará, en la figura del nómada, un modo de desmarcarse de sus predecesores y del tipo de escritor que sus mayores encarnaron. Celina Manzoni ha escrito con razón que, en las dos últimas décadas, "la itinerancia genera nuevas modalidades de escritura" (2009: 13). Cabría añadir que también genera nuevos iconos del escritor global.

En efecto, aunque suele confundirse con la del exiliado y/o la del cosmopolita, la figura del escritor nómada en Rey Rosa y Bolaño, tiene, a mi modo de ver, un significado muy diferente y se construye en una relación de oposición a la del gran intelectual cosmopolita moderno del boom (Guerrero 2013). Para cernir la especificidad de esta nueva figura que aparece en los noventa, no basta apelar tan solo a la lectura de Deleuze y Guattari, quienes, como es sabido, ponen a circular un vasto discurso sobre el nomadismo dentro del pensamiento posmoderno en tanto máquina de guerra excéntrica y contestataria que se opone al control institucional (Deleuze y Guattari 1980: 271). Además, me parece importante echar mano, en una perspectiva algo distinta, de la noción más contemporánea de "nomadismo crítico" propuesta por James Meyer como la antítesis del "nomadismo lírico" de la cultura romántica y moderna (Meyer 1997: 205). Y avanzo esto porque la figura del nómada en Bolaño y en Rey Rosa se despliega sobre el horizonte contemporáneo como una forma de internacionalización literaria que no se corresponde ya, insisto, ni con la tradición del exilio ni con la del cosmopolitismo latinoamericanos, propiamente dichos. Al contrario, el chileno y el guatemalteco se mueven en un nuevo contexto donde el nomadismo implica una revisión crítica de estas tradiciones tanto internamente, desde un punto de vista postnacional, como externamente, desde un punto de vista postcolonial, ambos a la luz de los cambios introducidos por la globalización. Advierto de inmediato qué entiendo aquí por "postnacional": no una más que improbable desaparición del sistema del Estado-nación en el mundo contemporáneo, sino una instancia en la crítica del legado del Estado-nación que se manifiesta en América Latina y en otros lugares del planeta como factor y producto de los procesos globalizadores. Y señalo asimismo que entiendo aquí por "postcolonial", siguiendo a Said y a Bhabha, no simplemente una situación histórica, sino una postura crítica frente a los legados del colonialismo y frente a los patrones ideológicos y cognitivos que Occidente le ha impuesto al planeta desde hace varios siglos (Bhabha 1994).

Desde la primera de esta dos perspectivas, Bolaño y Rey Rosa, como ya ha sido sugerido abundantemente, signan con sus obras, en los años noventa, el cierre de la agenda política de los setenta y acusan el quiebre de la utopía 
moderna que había erigido al escritor y el poeta comprometidos en ese personaje ideal en el que se reconciliaban, por fin, existencia y creación, literatura y acción. Aunque el caso del chileno se preste a discusión, no puede decirse que ninguno de nuestros dos autores reproduzca este icono ni que sean realmente unos "exilados" o que su estampa vagabunda autorice que se los califique de tales, pues el nomadismo es, para ellos, antes que nada, una forma de vida y no un estado transitorio. Aún más, es una elección asumida que no se traduce ni en una poética de la nostalgia ni en un programa político de vuelta a la patria, ni en una militancia internacionalista ni en una literatura abocada a repensar un país, su historia o su destino, como la del boom. Por el contrario, los dos se nutren de una suerte de feroz melancolía o de aguerrido desencanto en sus relaciones con Chile y Guatemala, y, a diferencia de lo que ocurrió con muchas personalidades del boom o del exilio latinoamericano, mal puede imaginárselos como representantes o portavoces de sus países o sus culturas. La razón de ello no solo se esconde en su individualismo sino en el hecho de que, en ambos, la figura del nómada encarna, a partir de los años noventa, la crisis de la temática nacional como el gran asunto central de la narrativa latinoamericana moderna.

Hijos de su tiempo, Bolaño y Rey Rosa dan cuenta de este cambio de paradigma que pone fin a una larga tradición cuyo origen se confunde con el nacimiento de nuestras repúblicas, pero que no se detiene realmente hasta la última década del siglo pasado. La coincidencia, a principios de los noventa, del estudio ya clásico de Doris Sommer, Foundational Fictions, the National Romances of Latin America (1991), y del libro de cuentos del entonces muy joven escritor porteño Rodrigo Fresán, Historia Argentina (1991), pueden considerarse como un símbolo del gran viraje que se anuncia. Ambos autores circunscriben, en el umbral de esa década, el momento clave que, por un lado, pone al desnudo la continuidad de la cuestión nacional como una imperiosa formación discursiva y, por otro, plantea la exigencia de escapar de ella y de ganar una nueva parcela de autonomía para la escritura literaria. A la pregunta de Sommer - ¿acaso la literatura latinoamericana ha hablado jamás de otra cosa que no sea la nación?corresponde así la respuesta de Fresán, quien, en su libro, se sirve de los tópicos del discurso nacional, para armar un carnaval irreverente y subversivo que abre una puerta de salida y apunta hacia la posibilidad de imaginar "el lado de afuera", como reza el título de uno de los cuentos, es decir, un espacio literario alternativo a ese en donde cohabitan desde siempre literatura y nación (Fresán 2009: 135).

Bolaño y Rey Rosa empiezan a publicar, como el propio Fresán, en un momento en que la interiorización de esta agenda marca un lindero entre las generaciones y su nomadismo, más allá o más acá de lo que signifique como experiencia individual, responde al proceso de construcción de una imagen de escritor que se inscribe en dicha agenda. De ahí que no sea posible entenderlo si no se lo articula a la vez con varias características que ambos comparten y que son asimismo rasgos de otros de sus compañeros de generación, a saber: la denuncia del nacionalismo literario, el esbozo de una literatura transnacional y la construcción de identidades alternativas y globales. Evidentemente, no es fácil distinguir un aspecto del otro porque los tres se funden y se confunden dentro 
de un mismo proceso. Pero lo que cuenta es que todos contribuyen a trazar una frontera entre un ayer y un hoy por lo que toca a la internacionalización de las últimas generaciones antes y después de la globalización.

Así, la crítica de los vínculos entre nación y literatura ya no adopta en los dos autores la forma tradicional de una queja sobre el provincianismo o sobre el regionalismo que limitaría la vocación "universal" (valgan las comillas) de nuestra producción literaria, tal y como la encontramos, por ejemplo, en Darío, en Borges o aún en los escritores del boom. Rey Rosa y Bolaño van mucho más lejos, pues su crítica incide en el vínculo político que ha unido desde siempre literatura y nación, y ha hecho de los escritores, a veces para bien y sobre todo para mal, cómplices del proyecto moderno de construcción de una cultura nacional. Así, el Carlos Wieder de Estrella distante (1996), poeta de vanguardia, torturador y asesino, al igual que el crítico literario de Nocturno de Chile (2000), son dos de los puntos extremos que alcanza en Bolaño una crítica que asocia el ejercicio de la literatura al poder y a la exaltación de los valores nacionales, una crítica que pone en escena la represión contra los diferentes en unas sociedades de suyo diversas y plurales. Subrayemos que tal postura es perfectamente cónsona con sus opiniones mordaces sobre la literatura chilena, argentina y, en general, latinoamericana, así como también con el tenor bastante conflictivo de su relación con Chile.

Por su parte, Rey Rosa, en un registro distinto al de Bolaño, describe en su primera novela, Cárcel de árboles (1992), un secreto campo de concentración en la selva centroamericana, donde conviven un grupo de prisioneros políticos a los que se les practicado una lobotomía y una bandada de loros a los que se ha domesticado para que aprendan a repetir interminablemente un soneto de Rubén Darío. La metáfora no podía ser más transparente ni más atroz y sería errado no vincularla no solo con la implacable pintura de Guatemala que recorre su obra sino con el cuestionamiento del papel de los escritores nacionales en la espiral de violencia que sacude desde hace varias décadas el país y casi toda Centroamérica. "Guatemala, la pequeña república donde la pena de muerte no fue abolida nunca, donde el linchamiento ha sido la única manifestación perdurable de organización social", escribe en Piedras encantadas (Rey Rosa 2002: 9). Años más tarde, en El material humano (2009) no se priva de hablarnos del gran padre de las letras guatemaltecas y premio Nobel, Miguel Ángel Asturias, en estos términos:

Encuentro por azar las fotocopias del artículo de Marta Elena Casaús donde habla de Fernando Juárez Muñoz, el contemporáneo de Miguel Ángel Asturias que, por influjo de la teosofía y autores como Mme Blavatski, Annie Besant y Jiddu Krishnamurti, sostenía que los indígenas mayas no pertenecían a una raza inferior y predicaba, ya en 1922, que para la formación de una verdadera nación positiva sería indispensable que los indígenas se incorporaran plenamente a la ciudadanía con iguales derechos y deberes que cualquier guatemalteco, que se les tomara en cuenta en su condición de elementos de riqueza... Desde luego, Miguel Ángel \& Co. no estaban de acuerdo. En aquel tiempo el futuro Premio Nobel escribía: En rigor de verdad, el indio psíquicamente reúne signos induda- 
bles de degeneración; es fanático, toxicómano y cruel. O: Hágase con el indio lo que con otras especies animales, como el ganado vacuno, cuando presentan síntomas de degeneración. (Rey Rosa 2009: 114)

No creo que haga falta pie de grabado. Baste recordar que cuando Rey Rosa se hace acreedor en Guatemala al Premio Nacional Miguel Ángel Asturias en 2004, provoca una sonada polémica al donar el dinero para que se cree un premio nacional para las literaturas en lenguas indígenas del país (Arroyave 2006).

Si el nomadismo del uno y el otro, como se ve, supone una crítica del vínculo moderno entre literatura y nación, la manera de salir de dicha relación no puede ser replanteando otra vez la pregunta por la viabilidad de la nación misma, como lo hicieron los escritores del boom, sino abriéndose hacia una poética trasnacional del extrañamiento y el desarraigo que marche al unísono con su ética de la aventura. Destaquemos que no es otra la estrategia que Benno Von Archimboldi sigue en 2666, para escapar de la tradición de una cultura como la alemana, donde el problema de las relaciones entre literatura y nación tiene matices aún más intensos y radicales que en Latinoamérica. Bolaño y Rey Rosa son como sus discípulos, pues pareciera que ambos van tras su huella al marcharse de sus países de origen y asociar su extranjería al arte de cultivar un imaginario del extremo, la frontera y el confín que trasgrede los límites anteriores y amplía las geografías de la novela latinoamericana. Como lo ha señalado ya Valeria de los Ríos, el mapa cognitivo de Bolaño no es el del Macondo de García Márquez, con su exotismo y sus linderos bien definidos, sino la aldea global que todos habitamos hoy y su continuo trasiego de gentes, mensajes e identidades. De los Ríos añade de seguido:
Arturo Belano, como el doble literario de Bolaño, se mueve indistintamente por Sonora, Santiago, África o un pueblo costero español. La lectura de la obra de Bolaño como mapa cognitivo ayuda a visualizar el universo complejo de historias, personajes y territorios creados por este autor y otorga, además, una dimensión política a la misma, inscribiendo y desestabilizando los ejes Norte- Sur, centro-periferia, civilización y barbarie, con una violencia inusitada. (De los Ríos 2008: 240)

Otro tanto podría decirse del Rey Rosa de los cuentos de Ningún lugar sagrado, o de las novelas La orilla africana (1999) y el El tren a Travancore (2001). Porque el uno y el otro intervienen, por un lado, en el contexto de los centros hegemónicos occidentales reescribiendo libremente episodios de su barbarie histórica, como el nazismo o el colonialismo, mientras, por otro lado, desplazan las fronteras de los imaginarios latinoamericanos hacia zonas de contacto inéditas dentro de una lógica intercultural periférica o Sur-Sur. Por ambas vías, lo que buscan, en tanto y en cuanto escritores nómadas, es, efectivamente, desestabilizar el orden heredado de la política colonial moderna y desplazar la alteridad de la literatura latinoamericana dentro de esa topología. Huelga subrayar que nada los separa tanto de la figura del escritor cosmopolita ni de la tradición de nuestro 
cosmopolitismo ilustrado, desde el modernismo hasta el boom, como esta crítica de las herencias coloniales que no puede concebirse sin el cuestionamiento del humanismo ni de la centralidad de Occidente como patrón histórico del universalismo. De ahí que ni en el fondo ni en la forma pueda asociarse el nomadismo de Bolaño y de Rey Rosa a la vieja reivindicación latinoamericana de ocupar un sillón en la República Mundial de las Letras. Si a algo habría que asociarlo más bien es a las rápidas transformaciones del planeta a las que estamos asistiendo desde la caída del muro de Berlín y al rediseño de una cartografía global donde ya no es tan fácil saber quién es el bárbaro, quién el excéntrico o quién el otro.

En este sentido, me parece no solo legítimo sino necesario interpretar la figura del nómada en Bolaño y en Rey Rosa como un fenómeno singular y distinto en el proceso de internacionalización de la literatura latinoamericana. Porque internacionalizarse ya no significa únicamente darse a conocer más allá de la nación sirviéndose a la vez de la identidad nacional como único pasaporte y preservando el orden geopolítico heredado del colonialismo como garante del éxito o el fracaso de dicha operación. Internacionalizarse significa, para estos nuevos nómadas globales, gestionar críticamente sus identidades híbridas desde una perspectiva postnacional -"muchas pueden ser las patrias de un escritor", dijo Bolaño (2004: 36) en el discurso de Caracas-y, al mismo tiempo, dibujar, con sus desplazamientos, mapas distintos del mundo contemporáneo que ya no obedecen a las lógicas tradicionales que regían las relaciones Norte-Sur, Centros-Periferias u Oriente-Occidente. Es más, al redefinir sus identidades a través de la construcción de una figura distinta del escritor, ambos abren sus culturas a la posibilidad de redefinirse de un modo inédito y las hacen participar en una problemática global, pero desde unos contextos históricos claramente locales y con un acento muy personal. Por eso no resulta difícil ver en sus trayectorias y en sus obras una repetida puesta en escena de las tensiones entre lo global y lo local que definen nuestra subjetividad contemporánea y que, a mi modo de ver, caracteriza su nomadismo como un "nomadismo crítico". Los dos lo encarnan además en la medida en que, con su actitud y sus ficciones, nos invitan a reflexionar en torno al presente y al pasado de las condiciones mismas de movilidad y circulación entre los espacios nacionales, internacionales y globales no solo en una dimensión literaria o artística sino también política y ética, como un asunto donde las representaciones no aparecen desligadas de sus efectos. No es otro el ejemplo que nos proporcionan muchos de los personajes y de las historias de novelas como 2666 o La orilla africana. Citemos al chileno Amalfitano, al alemán Benno Von Archimboldi o al marroquí Hamza cuyos destinos nos hablan en distintas lenguas de la movilidad de los migrantes en un mundo que se les ha vuelto a todos extranjero y donde todos acaban preguntándose, como el propio Bolaño, "pero, ¿dónde estaba nuestra casa?" (2000: 105). Y es que, en última instancia, el nomadismo crítico de nuestros dos autores acaba apuntando hacia la necesidad cada vez más afanosa de repensar la comunidad y la convivencia en un tiempo en que los viejos modelos parecen cada vez menos capaces de responder a las demandas actuales y en que la aparición de un nuevo sistema global aún sigue siendo una utopía. No es otra, en mi sentir, la tierra de 
nadie que recorren y circunscriben con sus movimientos, como si la expresión del desencanto se nutriera en ambos del fondo secreto de una esperanza o, cuando menos, de una cierta expectativa ante lo porvenir.

\section{OBRAS CITADAS}

Arroyave, Nancy (2006): "Rey Rosa: Mientras las lenguas estén vivas, puede haber algo que gozar de ellas". En: Prensalibre.com, 27 de enero. Disponible en <http://www. prensalibre.com/cultura/Rey-Rosa-lenguas-puede-gozar_0_133188038.html>. Última visita: 12.06.2013.

Bhabha, H.K., (1994): The Location of Culture. Nueva York / Londres, Routledge.

Bolaño, Roberto (2000): Tres. Barcelona, El Acantilado.

- (2002): Putas asesinas. Barcelona, Anagrama. (2004): Entre Paréntesis. Barcelona, Anagrama.

Castellanos Moya, Horacio (2009): "Sobre el mito Bolaño". En: Lanacion.com, 19 de septiembre. Disponible en <http://www.lanacion.com.ar/1176451-sobre-el-mitobolano>. Última visita: 12.06.2013.

Deleuze, Gilles, y Guattari, Felix (1980): Capitalisme et schizophrénie 2: Mille plateaux. París, Minuit

De los Ríos (2008): "Mapas y fotografías de Roberto Bolaño". En: Edmundo Paz Soldán y Gustavo Faveron Patriau (eds.): Bolaño salvaje. Barcelona, Candaya, pp. 237-258.

Fresán, Rodrigo (2009): Historia Argentina [1991]. Barcelona, Anagrama.

Gray, Jeffrey (2007): "Placing the Placeless: A Conversation with Rodrigo Rey Rosa". En: A Contracorriente. Una revista de historia social y literatura de América Latina, vol. 4 n. ${ }^{\circ}$, pp. 160-186. Disponible en <http://www.ncsu.edu/project/acontracorriente/ winter_07/Gray.pdf>. Última visita: 12.06.2013.

Guerrero, Gustavo (2013): "Boom y cosmopolitismo". Alicante, Biblioteca Virtual Miguel de Cervantes, pp. 1-10. Disponible en <http://www.cervantesvirtual.com/obra/boomy-cosmopolitismo>. Última visita: 12.06.2013.

Manzi, Joaquín (2002): "El secreto de la vida (no está en los libros)". En: Celina Manzoni (ed.): Roberto Bolaño, la escritura como tauromaquia. Buenos Aires, Corregidor, pp. 153-165.

Manzoni, Celina (2009): Errancia y escritura en la literatura latinoamericana contemporánea. Alcalá la Real, Alcalá Grupo Editorial.

Meyer, James (1997): "Nomads" En: Parkett, n. 49, pp. 205-209.

Piglia, Ricardo (2001): Crítica y ficción [1986]. Barcelona, Anagrama.

Rey Rosa, Rodrigo (2002): Piedras encantadas. Barcelona, Seix Barral. (2009): El material humano. Barcelona, Anagrama. 